\title{
Risk Factors for Amputation in Patients with Diabetic Foot Diseases in Sokoto, Nigeria
}

\author{
M. Oboirien ${ }^{*}$, S. P. Agbo², L. O. Ajiboye ${ }^{1}$ \\ ${ }^{1}$ Department of Orthopaedics \& Trauma, Usmanu Danfodiyo University Teaching Hospital, Sokoto, Nigeria \\ ${ }^{2}$ Department of Surgery, Usmanu Danfodiyo University Teaching Hospital, Sokoto, Nigeria \\ Email: agbostephen@yahoo.com, ajiboyelo@yahoo.com, *moboirien@yahoo.com
}

How to cite this paper: Oboirien, M., Agbo, S.P. and Ajiboye, L.O. (2018) Risk Factors for Amputation in Patients with Diabetic Foot Diseases in Sokoto, Nigeria. Health, 10, 645-653.

https://doi.org/10.4236/health.2018.105050

Received: April 25, 2018

Accepted: May 25, 2018

Published: May 28, 2018

Copyright $\odot 2018$ by authors and Scientific Research Publishing Inc. This work is licensed under the Creative Commons Attribution International License (CC BY 4.0).

http://creativecommons.org/licenses/by/4.0/

\begin{abstract}
Background: Diabetic foot disease is a foot that exhibits any pathology that results directly from diabetic mellitus or any long-term chronic complication of diabetes mellitus. The aim of the study was to determine the risk factors and indications for amputations in diabetics and to correlate these risks with mortality in our environment. Patients and methods: An audit of consecutive patients who were referred and had amputation as a result of diabetic foot diseases in a tertiary institution in Sokoto, northwest Nigeria over a 2-year period was done. Parameters studied using a predetermined protocol included the bio-data, socioeconomic status, vascular status, Meggit-Wagner grading status, indications for amputation and outcome. Results: There were nineteen amputations done in 19 patients with age range of 45 to 75 years and a mean age of $57.94 \pm 8.92$. There were more females (68\%) than males (32\%) giving a M:F ratio of 1:2. Forty-one percent of patients were housewives and $89.5 \%$ were of middle socioeconomic status. Seventy-three percent of the patients had no formal education while $31.6 \%$ has had diabetes for between 6 and 10 years. All the patients had comorbidity and $78.9 \%$ were Wagner's grade V. Ascending cellulitis and sepsis (68.4\%) was the commonest indication for amputation. Trans femoral amputation was carried out in $47.4 \%$ and $21.1 \%$ had reamputation. A mortality rate of $15.8 \%$ was recorded and $52.6 \%$ defaulted from follow-up. There was no correlation between the risk factors and outcome in these patients $(p>0.05)$. Conclusions: Amputation was commonly done in the female diabetic housewife with no formal education. Educating these patients, improving their socioeconomic status will help them modify behaviours and identify foot at risk and complications.
\end{abstract}

\section{Keywords}

Diabetic Foot Diseases, Amputation, Risk Factors 


\section{Introduction}

Diabetic foot disease has been described as a foot that exhibits any pathology that results directly from diabetic mellitus or any long-term chronic complications of diabetes mellitus. The diabetic foot is prone to neuroarthropathy, ulceration, infections (Cellulitis, deep skin and soft tissue infections, acute and chronic Osteomyelitis), and Gangrene. Cellulitis occurs 9 times more frequently in diabetics than non-diabetics. Osteomyelitis of the foot is 12 times more frequent in diabetics than non-diabetics [1] [2]. Hospital-based studies showed that the prevalence of limb ulceration was between $11.7 \%$ and $19.1 \%$ among individuals with diabetes in Nigeria [3] [4]. It is a major surgical problem in our environment accounting for $7 \%$ of amputations in adults [5]. In the early 2000, it was the second commonest indication for amputation in Jos, Nigeria [6]. Diabetes is the leading cause of non-traumatic lower extremity amputations in the United States, with approximately 5\% of diabetics developing foot ulcers each year and 1\% requiring amputation [7]. Diabetic foot diseases are responsible for more hospitalizations than any other complication of diabetes. In some instances, the development of foot lesions will be the first presentation of diabetics mellitus as patients may be unaware of the presence of the disease [6] [8]. Late presentations, sepsis are hallmark features of the disease in our environment often resulting in mortality [9] [10]. The purpose of this study was to determine the risk factors for amputations in patients with diabetic foot diseases and to correlate these risks with mortality.

\section{Patients and Methods}

It was a retrospective audit of consecutive patients who were referred for and had amputation as a result of diabetic foot diseases in Sokoto, northwest Nigeria over a 2 year period from January 2016 to December 2017. Parameters studied using a predetermined protocol included the bio-data, socioeconomic status, vascular status as determined by ankle-brachial index and Doppler ultrasound, Meggit-Wagner grading status. Other parameters included presence or absence of Co-morbidity, duration of diabetics and indications for amputation. Outcome measures included postoperative complications and mortality. Clinical assessment of the foot lesion was carried out noting presence of gangrene, sepsis and ulcers. Ankle brachial index was also assessed while Doppler ultrasound was done in some patients and this was used to determine the nature of amputation to be done. The foot lesions were graded from 0 to 5 using the classification of Meggit and Wagner. Diabetic control was done by the endocrinologist. We also determined the duration of hospital stay and follow-up. Patients who required only serial debridement with no amputation were excluded from the study. Results are presented in tabular and graphical forms.

\section{Results}

Nineteen amputations were done in 19 patients with age range of 45 to 75 years 
and a mean age of $57.94 \pm 8.92$. There were more females $(68 \%)$ than males (32\%) giving a M: F ratio of 1:2. Forty-two percent of patients were housewives and $89.5 \%$ were of middle socioeconomic status. Seventy-three percent of the patients had no formal education Table 1 . Most patients $57.9 \%$ have had diabetes for between 6 to 15 years Figure 1. All the patients had comorbidity and 78.9\% were Wagner's grade V. Ascending cellulitis and sepsis (68.4\%) was the commonest indication for amputation. Trans femoral amputation was carried out in $47.4 \%$ Table 2 . The complications showed that deep wound infection was $36.8 \%$ and $21.1 \%$ had re-amputation Figure 2 . A mortality rate of $15.8 \%$ was recorded and $52.6 \%$ defaulted from follow-up Figure 3. There was no correlation between the risk factors and outcome in these patients $(p>0.05)$.

\section{Discussion}

The results of this study showed that the mean age of those that had amputation as a result of diabetic foot diseases was the same for patients with Type 2 diabetes(T2DM). Type 2 diabetes is traditionally referred to as adult-onset diabetes and it accounts for $90 \%$ to $95 \%$ of cases of diabetes with individuals being able to produce insulin but unable to adequately use it as a result of end organ insulin resistance [11]. A cross-sectional study conducted across eight cities in Pakistan showed a prevalence rate of diabetic foot syndrome in type 2 was $13.9 \%$ [12]. In Thailand, about half of patients with type 2 diabetes have an intermediate or high risk of developing foot ulcers [13]. Studies have shown that a considerable proportion of people with T2DM have microvascular complications and/or peripheral arterial disease at the time of, and possibly years before diagnosis [14].

Table 1. Demographic variables, occupation, educational and socioeconomic status.

\begin{tabular}{|c|c|c|c|}
\hline \multicolumn{2}{|c|}{ Variables } & \multirow[t]{2}{*}{ Frequency } & \multirow[t]{2}{*}{ Percentage } \\
\hline Age (mean) & $57.94 \pm 8.2$ & & \\
\hline \multirow[t]{2}{*}{ Sex } & Male & 6 & 31.6 \\
\hline & Female & 13 & 68.4 \\
\hline \multirow[t]{4}{*}{ Occupation } & civil servant & 1 & 5.3 \\
\hline & business & 4 & 27.4 \\
\hline & Housewife & 8 & 42.1 \\
\hline & Faming & 6 & 31.6 \\
\hline \multirow[t]{4}{*}{ Educational level } & None & 14 & 73.7 \\
\hline & Primary & 2 & 10.5 \\
\hline & Secondary & 2 & 10.5 \\
\hline & Tertiary & 1 & 5.3 \\
\hline Socioeconomic & Low & 1 & 5.3 \\
\hline Middle & Middle & 17 & 89.4 \\
\hline High & High & 1 & 5.3 \\
\hline
\end{tabular}


Table 2. Clinical variables, indications and level of amputation.

\begin{tabular}{|c|c|c|c|}
\hline \multicolumn{2}{|c|}{ Variables } & \multirow{2}{*}{$\begin{array}{c}\text { Frequency } \\
7\end{array}$} & \multirow{2}{*}{$\begin{array}{c}\text { Percentage } \\
36.8\end{array}$} \\
\hline Doppler USS & Occlusion & & \\
\hline & No Occlusion & 12 & 63.2 \\
\hline Ankle brachial & $0.5-0.9$ & 3 & 15.8 \\
\hline \multirow[t]{2}{*}{ Index } & $<0.5$ & 4 & 21.1 \\
\hline & Not done & 12 & 63.2 \\
\hline \multirow[t]{2}{*}{ Wagner's stage } & IV & 4 & 21.1 \\
\hline & V & 15 & 78.9 \\
\hline Indications for & ascending cellulitis/sepsis & 13 & 68.4 \\
\hline \multirow[t]{2}{*}{ amputations } & wet gangrene & 4 & 21.1 \\
\hline & dry gangrene & 2 & 10.5 \\
\hline level ofl & Transfemoral & 9 & 47.4 \\
\hline amputation & Transtibial & 8 & 42.1 \\
\hline ray amputation & & 2 & 10.5 \\
\hline
\end{tabular}

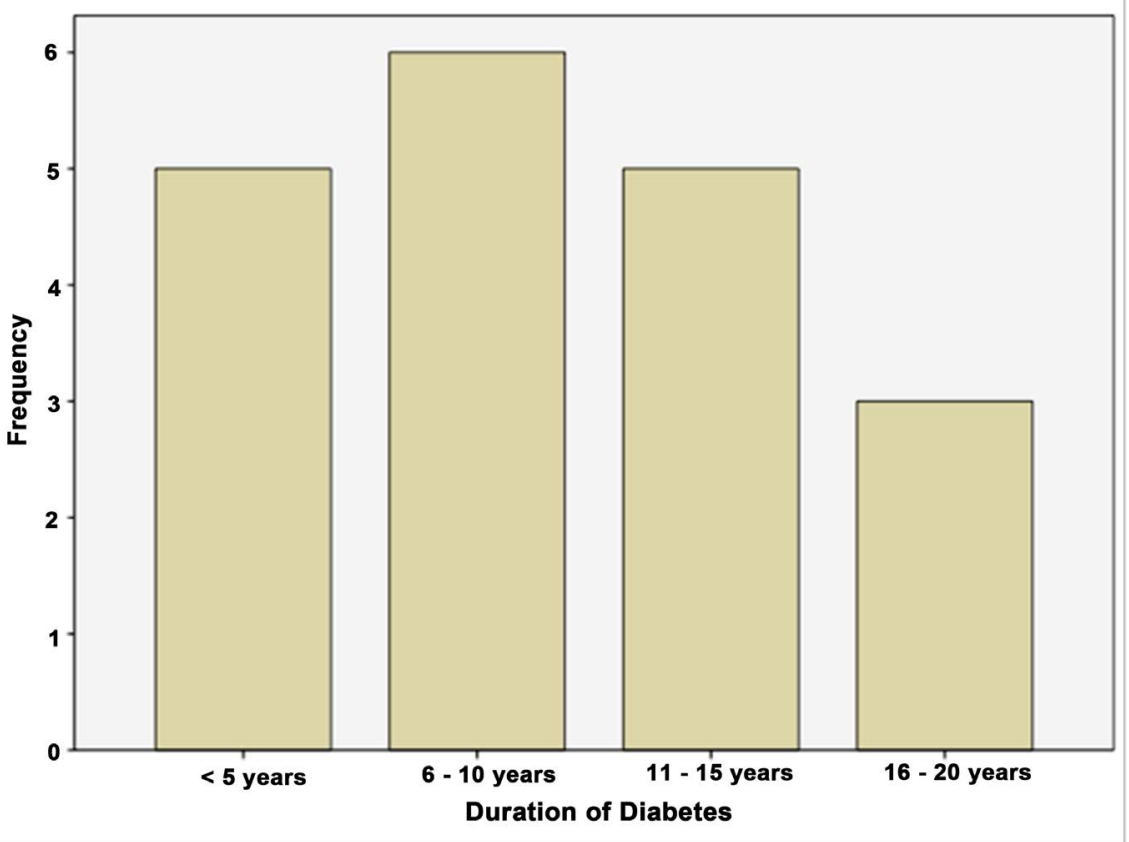

Figure 1. A bar chart showing the duration of diabetes.

[15]. Persistent hyperglycemia contributes to the development of neuropathy affecting the motor, sensory and autonomic systems. These in addition to poor vision, reduced skin oxygenation, Charcot joint, hammer/claw toes have been found to place patients at higher risk for ulceration [16] [17].

Our study showed that more women came down with serious foot condition necessitating amputation even though the incidence of T2DM is more common 


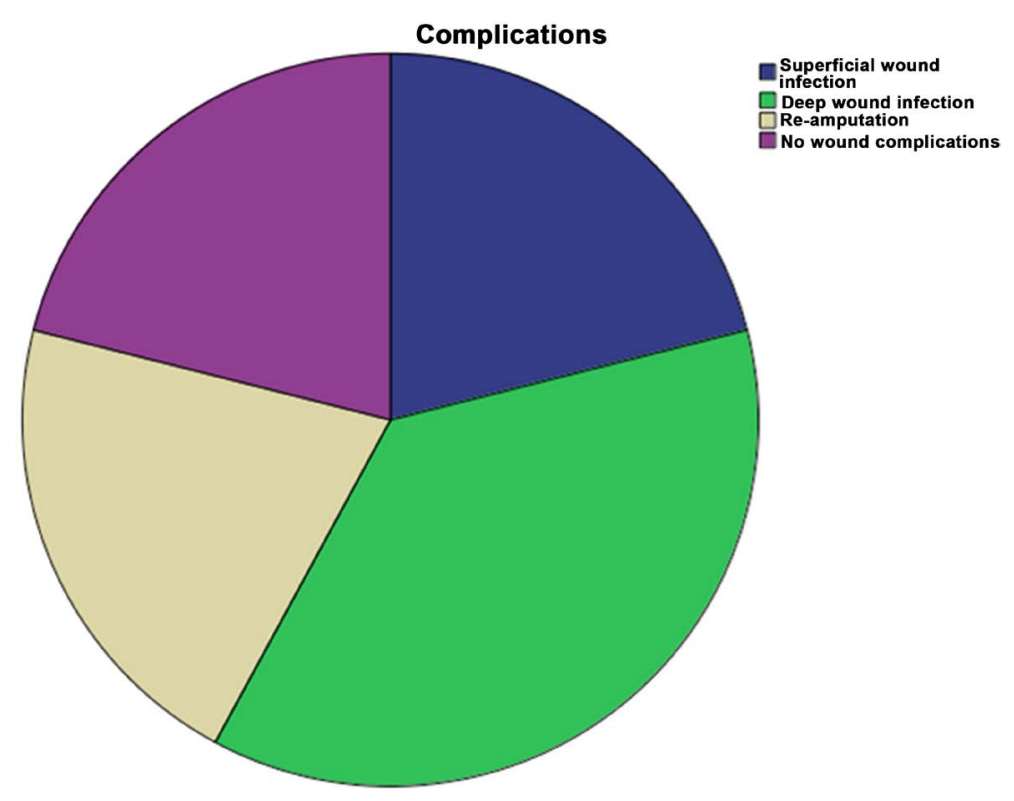

Figure 2. A pie chart showing complications following amputations.

\section{FREQUENCY}

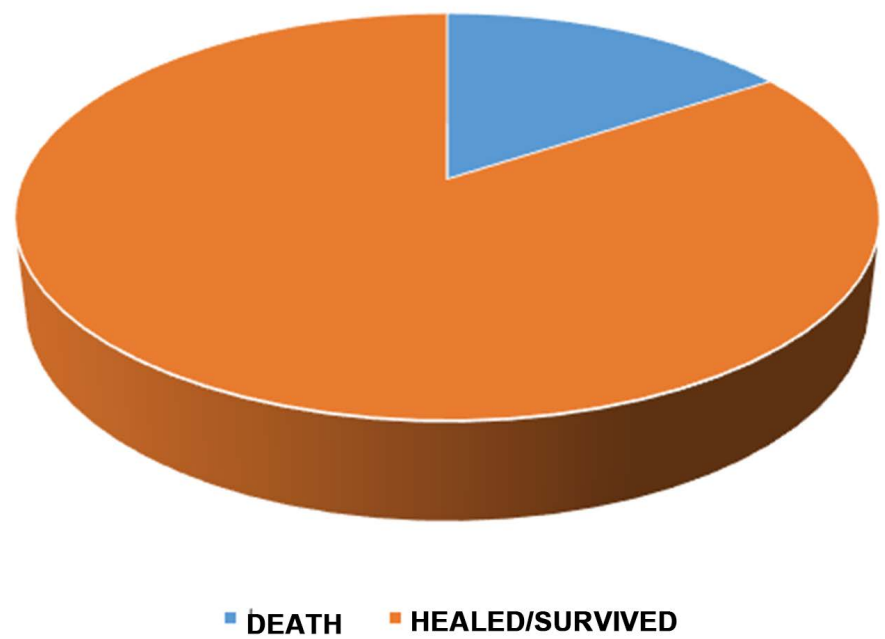

Figure 3. Outcome of patients who had amputation.

in males worldwide [18]. Men tend to be diagnosed with T2DM at a lower body mass index than women, but women have a stronger-obesity diabetic risk association and according to a systematic analysis females tend to be more obese than men. In addition, more women are overweight or obese after the age of 45 years, whereas more males are overweight at younger age [19]. There is a strong association between increase of body mass index (BMI) and diabetes risk, despite similar curvilinear associations between increasing BMI and diabetes risk in both sexes [20]. Sex specific difference in complications and co-morbidities of diabetics have been noted to occur more in women than men and these include, physical limitations, cognitive limitations, depression and anxiety [20] [21]. 
Social factors, like low educational level, occupation, and income, can contribute to unhealthy lifestyle behavior and social disparities and thus are related to higher risk of obesity and T2DM particularly in women [22] [23]. Social economic status (SES), assessed by educational level, position, and income, is inversely associated with prevalence of obesity and T2DM in developed countries [24]. A study found an association between low education and income and self-reported diabetes after controlling for obesity and physical activity in women [25]. Meta-analysis through case-control and cohort studies has shown that low SES is an important risk factor for T2DM in both sexes worldwide [26] [27]. A longitudinal population-based study, looking at childhood SES, assessed from fathers' occupation or education, found it to be a strong predictor of diabetes, especially among women [28].

Most patients in our study were housewives with no visible means of income and largely dependent on their spouses and children. Some are widows without social support and assessing healthcare and following health advise is a problem amongst them. Late presentation of the disease as seen in our studies makes blood sugar control difficult and precludes chances for limb salvage. Ascending cellulitis and sepsis were the common indications for emergency amputations in our study and this was done in most cases to reduce mortality and morbidity. Surveillance for foot at risk, screening for neuropathy, surgical debridement, use of hyperbaric oxygen has been found to increase chances of limb salvage but only for early cases [29]. Arterial disease and neuropathy have emerged as the only limb-specific risk factors for amputation and this are prominent features in the disease especially in grade IV and V [30].

Reasons for trans-femoral amputation in our study were largely due to the extent of the disease as attempt was made to avoid areas of cellulitis. Other reasons were the clinical assessment of perfusion by the ABI and Doppler USS. Acceptance of an above knee amputation in our environment sometimes posses a herculean task. In cases where compromised is reached for a below the knee amputation, the rate of re-amputation was high because of poor healing and increasing morbidity. The reasons for the lowest frequency of amputation in those with diabetes of duration 16 - 20 years could be that they had type 1 diabetes mellitus (T1DM) considering the average age in our study. In TIDM, early detection and management will reduce the incidence of complications.

The mortality rate noted in our study was high and the reason was the presence of comorbidity and the progression of the disease. Diabetics control is sometimes difficult in the presence of sepsis.

\section{Conclusion}

Amputation was commonly done in the female diabetic housewife with no formal education. Sex/gender though not a modifiable risk factor, educating these patients, improving their socioeconomic status will help them modify behaviours and identify foot at risk and complications. 


\section{Acknowledgements}

All named authors meet the International Committee of Medical Journal Editors (ICMJE) criteria for authorship for this manuscript and take responsibility for the integrity of the work as a whole. We acknowledge our physician colleagues for the commitment shown in the management of these patients.

\section{Conflict of Interest}

The authors declare that they have no competing interests.

\section{Ethical Approval}

All procedures performed in this study were conducted in accordance with the good clinical practice, ethical standards of the institutional research committee and with the 1964 Helsinki declaration and its later amendments.

\section{Informed Consent}

Informed consent was obtained from all individual participants included in the study.

\section{Funding}

We declare that no funding was received for this study.

\section{References}

[1] Ramsey, S.D., Newton, K., Blough, D., McCulloch, D.K., Sandhu, N., Reiber, G.E. and Wagner, E.H. (1990) Incidence, Outcomes, and Cost of Foot Ulcers in Patients with Diabetes. Diabetes Care, 22, 382-387. https://doi.org/10.2337/diacare.22.3.382

[2] Ragnarson, T.G. and Apelqvist, J. (2004) Health-Economic Consequences of Diabetic Foot Lesions. Clinical Infectious Diseases, 39, S132-139. https://doi.org/10.1086/383275

[3] Unachukwu, C., Babatunde, S. and Ihekwaba, A.E. (2007) Diabetes, Hand and/or Foot Ulcers: A Cross-Sectional Hospital-Based Study in Port Harcourt, Nigeria. Diabetes Research and Clinical Practice, 75, 148-152. https://doi.org/10.1016/j.diabres.2006.05.016

[4] Fard, A.S., Esmaeizadeh, M. and Larijani, B. (2007) Assessment and Treatment of Diabetic Foot Ulcer. International Journal of Clinical Practice, 61, 1931-1938.

[5] Oboirien, M., Agbo, S.P. and Ismail, S. (2010) Indications and Pattern of Extremity Amputations in Sokoto, North-West Nigeria. Nig J of Othopaedics and Trauma, 9 , 56-57.

[6] Nwadiaro, H.C., Obekpa, P.O. and Deshi, P.J. (2000) Amplitude of Amputations. Nigerian Journal of Surgical Sciences, 10, 44-48.

[7] Pecoraro, R.E., Reiber, G.E. and Burgess, E.M. (1990) Pathway to Diabetic Limb Amputation. Basis for Prevention. Diabetes Care, 13, 513-521.

https://doi.org/10.2337/diacare.13.5.513

[8] Desalu, O.O., Salawu, F.K., Jimoh, A.K., Adekoya, A.O., Busari, O.A. and Olokoba, A.B. (2011) Diabetic Foot Care: Self Reported Knowledge and Practice among Patients Attending Three Tertiary Hospital in Nigeria. Ghana Medical Journal, 45, 
60-65. https://doi.org/10.4314/gmj.v45i2.68930

[9] Olaolorun, D.A. (2001) Amputations in General Practice. West African Journal of Medicine, 8, 133-135.

[10] Umebese, P.F.A. and Ogbemudia, A.O. (1998) Management of Diabetic Foot: Objective Results in 40 Patients Using a New Diabetic Foot Severity Score. Nig J Surg, 5, 10-12.

[11] Richard, L.U., Andrew, J.R., John, A.D., James, D. and Michael, M. (2014) Diabetes Mellitus: Musculoskeletal Manifestations and Perioperative Considerations for the Orthopaedic Surgeon. JAAOS, 22, 183-192. https://doi.org/10.5435/JAAOS-22-03-183

[12] Khan, A. and Junaid, N. (2017) Prevalence of Diabetic Foot Syndrome amongst Population with Type 2 Diabetes in Pakistan in Primary Care Settings. Journal of Pakistan Medical Association, 67, 1818-1824.

[13] Sarinnapakorn, V., Sunthorntepwarakul, T., Deerochanawong, C., Niramitmahapanya, S. and Napartivaumnuay, N. (2016) Prevalence of Diabetic Foot Ulcers and Risk Classifications in Type 2 Diabetes Mellitus Patients at Rajavithi Hospital. Journal of the Medical Association of Thailand, 99, S99-105.

[14] Musa, A.A. (2012) Diabetic Foot Lesions as Seen in Nigerian Teaching Hospital: Pattern and a Simple Classification. East African Journal of Public Health, 9, 50-52.

[15] Khalil, S.A., Megallaa, M.H., Rohoma, K.H., Guindy, M.A., Zaki, A., Hassanein, M., Malaty, A.H., Ismael, H.M., Kharboush, I.F., El Kafash, D.N., Sallam, H.N. and Desouky, I.A. (2018) Prevalence of Chronic Diabetic Complications in Newly Diagnosed versus Known Type 2 Diabetic Subjects in a Sample of Alexandria Population, Egypt. Current Diabetes Reviews [Epub Ahead of Print].

[16] Chung, S.S., Ho, E.C., Lam, K.S. and Chung, S.K. (2003) Contribution of Polyol Pathway to Diabetes-Induced Oxidative Stress. Journal of the American Society of Nephrology, 14, S233-S236. https://doi.org/10.1097/01.ASN.0000077408.15865.06

[17] Boyko, E.J., Ahroni, J.H., Stensel, V., Forsberg, R.C., Davignon, D.R. and Smith, D.G. (1999) A Prospective Study of Risk Factors for Diabetic Foot Ulcer: The Seattle Diabetic Foot Study. Diabetes Care, 22, 1036-1042. https://doi.org/10.2337/diacare.22.7.1036

[18] International Diabetes Federation (2013) IDF Diabetes Atlas. 6th Edition, International Diabetes Federation, Brussels, Belgium.

[19] Ng, M., Fleming, T., Robinson, M., et al. (2014) Global, Regional, and National Prevalence of Overweight and Obesity in Children and Adults during 1980-2013: A Systematic Analysis for the Global Burden of Disease Study 2013. The Lancet, 384, 766-781. https://doi.org/10.1016/S0140-6736(14)60460-8

[20] Bray, G.A. (2004) Medical Consequences of Obesity. The Journal of Clinical Endocrinology \& Metabolism, 89, 2583-2589. https://doi.org/10.1210/jc.2004-0535

[21] McCollum, M., Hansen, L.S., Lu, L. and Sullivan, P.W. (2005) Gender Differences in Diabetes Mellitus and Effects on Self-Care Activity. Gender Medicine, 2, 246-254. https://doi.org/10.1016/S1550-8579(05)80054-3

[22] Lee, D.S., Kim, Y.J. and Han, H.R. (2013) Sex Differences in the Association between Socio-Economic Status and Type 2 Diabetes: Data from the 2005 Korean National Health and Nutritional Examination Survey (KNHANES). Public Health, 127, 554-560. https://doi.org/10.1016/j.puhe.2013.02.001

[23] Kautzky-Willer, A., Dorner, T., Jensby, A. and Rieder, A. (2012) Women Show a Closer Association between Educational Level and Hypertension or Diabetes Melli- 
tus than Males: A Secondary Analysis from the Austrian HIS. BMC Public Health, 12, 392. https://doi.org/10.1186/1471-2458-12-392

[24] Tang, M., Chen, Y. and Krewski, D. (2003) Gender-Related Differences in the Association between Socioeconomic Status and Self-Reported Diabetes. International Journal of Epidemiology, 32, 381-385. https://doi.org/10.1093/ije/dyg075

[25] Rathmann, W., Haastert, B., Icks, A., et al. (2005) Sex Differences in the Associations of Socioeconomic Status with Undiagnosed Diabetes Mellitus and Impaired Glucose Tolerance in the Elderly Population: The KORA Survey 2000. European Journal of Public Health, 15, 627-633. https://doi.org/10.1093/eurpub/cki037

[26] Agardh, E., Allebeck, P., Hallqvist, J., Moradi, T. and Sidorchuk, A. (2011) Type 2 Diabetes Incidence and Socio-Economic Position: A Systematic Review and Meta-Analysis. International Journal of Epidemiology, 40, 804-818. https://doi.org/10.1093/ije/dyr029

[27] Rivera, L.A., Lebenbaum, M. and Rosella, L.C. (2015) The Influence of Socioeconomic Status on Future Risk for Developing Type 2 Diabetes in the Canadian Population between 2011 and 2022: Differential Associations by Sex. International Journal for Equity in Health, 14, 101. https://doi.org/10.1186/s12939-015-0245-0

[28] Maty, S.C., Lynch, J.W., Raghunathan, T.E. and Kaplan, G.A. (2008) Childhood Socioeconomic Position, Gender, Adult Body Mass Index, and Incidence of Type 2 Diabetes Mellitus over 34 Years in the Alameda County Study. American Journal of Public Health, 98, 1486-1494. https://doi.org/10.2105/AJPH.2007.123653

[29] Howell, R.S., Criscitelli, T., Woods, J.S., Gillette, B.M., Brem, H. and Gorenstein, S. (2018) A Perioperative Approach to Increase Limb Salvage When Treating Foot Ulcers in Patients with Diabetes. AORN Journal, 107, 431-440. https://doi.org/10.1002/aorn.12099

[30] Boyko, E.J., Seelig, A.D. and Ahroni, J.H. (2018) Limb- and Person-Level Risk Factors for Lower-Limb Amputation in the Prospective Seattle Diabetic Foot Study. Diabetes Care, 41, 891-898. https://doi.org/10.2337/dc17-2210 